\title{
BEHAVIOR AND DESIGN ASPECTS OF CONCRETE BEAMS REINFORCED WITH HYBRID STEEL-GFRP BARS
}

\author{
Mohamed A. Safan \\ Civil Engineering Department, Faculty of Engineering, Minoufiya University, Egypt
}

\begin{abstract}
This paper aims at investigating the structural behavior of simply supported concrete beams reinforced with hybrid reinforcement consisting of steel and glass fiber reinforced polymer (GFRP) bars. The proposed system utilizes the merits of ductility and stiffness provided by the steel reinforcement and the anticorrosion characteristics of GFRP. While, the steel bars were provided with an increased concrete cover to ensure extra protection against corrosion, the GFRP bars were laid near the bottom tension surface of test beams to control cracking. Different parameters influencing the structural behavior including the steel and the GFRP reinforcement ratios and the configuration of shear reinforcement were considered. The steel stirrups were used to confine only the elevated steel bars or to confine both the steel and the GFRP bars. A total of twelve beams were tested in flexure under four-point loading till failure. The load-deflection response, the cracking patterns and the failure modes were recorded. A design equation was proposed to predict the ultimate load of the hybrid test beams. The test results showed that the performance of the proposed system was successful in maintaining the flexure strength with adequate stiffness and improved the cracking characteristics compared to counterpart beams with conventional reinforcement.

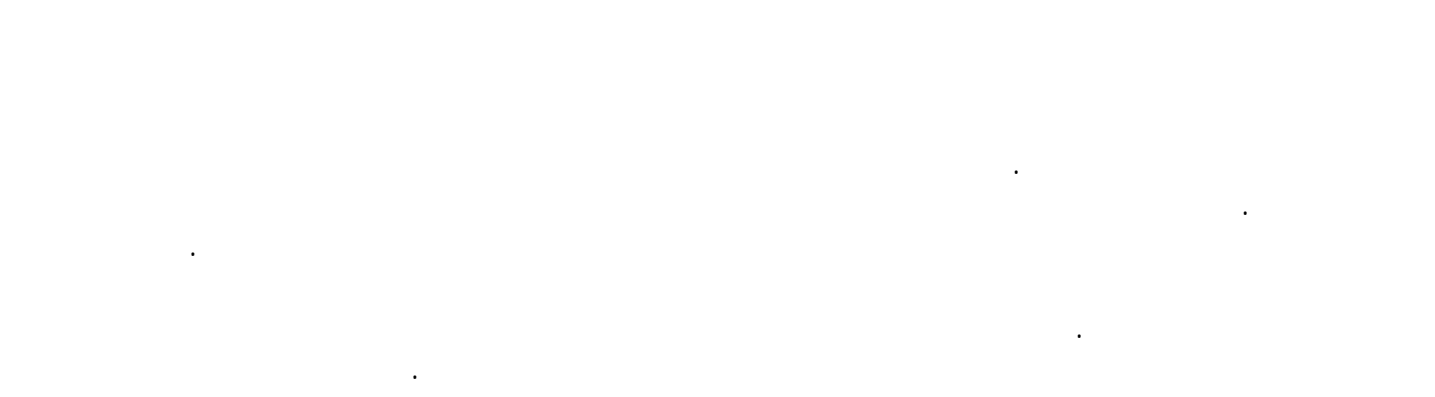

Keywords: hybrid reinforcement; GFRP; durability; corrosion; deflection; cracking.

\section{INTRODUCTION}

Corrosion of steel reinforcement in concrete structures induces serious threat to the integrity and safety of structural concrete members. The steel bars are protected against corrosion due to the high alkalinity of concrete and the formation of a passive protecting film on the surface of the bars. The alkalinity of concrete is reduced with time due to carbonation and corrosion begins when the passive layer is penetrated by oxygen, moisture and aggressive agents [1]. However, corrosion does not begin in all steel bars at the same time. Corrosion occurs usually first in the steel bars near the outer surfaces and especially at the corners of the structural element. This trend is due to the high carbonation rate, easy entry of oxygen and moisture and the lower resistance to spalling at the corners. Spalling of the concrete cover around the outer bars accelerates the corrosion of the inner steel bars [2]. Costly rehabilitation works represented a challenge to seek technical solutions and alternatives. Traditional corrosion remedies including the use of stainless steel, epoxy coatings, cathodic protection, chemical inhibitors and treatment of concrete surfaces are either expensive or of limited technical value [3]. More recently, fiber reinforced polymer (FRP) bars were introduced as a possible alternative to steel reinforcement in construction and rehabilitation works due to the high specific tensile strength and the non-corrosive nature. Unfortunately, mono-fiber FRP bars exhibit a linear elastic behavior up to failure under tensile stress. This property makes the structural elements brittle when mono-fiber FRP bars are used as internal reinforcement. Therefore, the 
design criterion of FRP reinforced flexure beams according to the ACI 440.1R-06 guide [4] has been based on concrete crushing rather than on the rupture of the FRP bras aiming at improving the beam ductility by making use of the plastic deformation of concrete in compression. Also, FRP bars incorporating glass fibers have a relatively low modulus of elasticity that is only about two times that of conventional concrete [5]. For this reason, concrete beams reinforced with GFRP show larger defections and wider cracks than counterpart steelreinforced concrete beams with the same cross section and reinforcement area [6-9]. Consequently, the design criterion of flexure beams has been based on providing a reinforcement ratio that is higher than the balanced ratio to ensure failure due to concrete crushing. This would typically mean increased construction cost due to the initial relatively high price of FRP reinforcement. At this stage, it would seem that replacing the steel with FRP bars is not convenient in structural elements where deflection and cracking width are critical.

The use of GFRP bars as internal reinforcement can be optimized by using hybrid steel-GFRP reinforcement systems in which the GFRP bars are placed near the outer tension face, while the steel bars are elevated to upper levels. In normal service, this combination of steel and FRP reinforcement offers improved serviceability and lower cost than FRP reinforcement, and longer service life than steel reinforcement. The use of steel reinforcement allows an under-reinforced design, with a limited amount of FRP reinforcement. While, the yielding of the steel ensures ductility, the contribution of the FRP increases the ultimate capacity [10].

This system was first proposed by Arya, Ofori and Pirathapan [11] considering that increasing the concrete cover is a very effective way of controlling the corrosion of steel since the penetration of carbonation and chloride roughly follows a square root of time function [12]. In their experimental work, GFRP bars of different diameters were used to provide additional reinforcement areas corresponding to 20,30 and 80 percent of the steel reinforcement area. All beams were tested up to a serviceability design moment corresponding to 55 percent of the theoretical ultimate moment of the control beam with elevated steel bars. Within this loading range, it was demonstrated that the load-deflection response and cracking loads were not significantly altered by the placement of the GFRP bars, while the cracking widths were effectively reduced to acceptable serviceability limits according to BS8110 [13] compared to the control beam. Later, Tan [14] tested concrete beams reinforced with a combination of aramid fiber reinforced polymer (AFRP) and steel bars. The investigation addressed the contribution of the tensile force provided by the AFRP rebars at ultimate loads by altering the AFRP/steel reinforcement ratio. It was concluded that the tested beams had adequate serviceability when the contributing tensile force from AFRP bars was no more than half the total tensile force.

Aiello and Ombres [15] analyzed the serviceability and flexure capacity of a set of hybrid AFRP/steel reinforced concrete beams. The results of their experimental and theoretical investigation confirmed that adding sufficient steel reinforcement improved the serviceability provided by the hybrid reinforcement. With a reasonable ratio of steel to FRP, hybrid steel-FRP reinforced concrete beams deform less than FRP-reinforced concrete beams as the presence of steel reinforcement reduces the crack width and the crack spacing values. Also, they found that when the reinforcement ratio exceeded the balanced reinforcement ratio for FRP-reinforced concrete beams, the contribution of the steel reinforcement to the beams' flexure capacity was less than $15 \%$. A model based on the moment-curvature law for cross sections considering tension stiffening of concrete could be used to predict the flexural behavior of hybrid steel-FRP reinforced concrete beams. They concluded that the design models for the effective moment of inertia developed for steelreinforced concrete beams proposed by the ACI31895 code [16] and for FRP-reinforced concrete beams proposed by the ACI 440R-96 report [5] could not be applied to hybrid steel-FRP reinforced concrete beams without calibration.

Leung and Balendran [10] tested concrete beams reinforced with a combination of GFRP and steel bars placing the GFRP bars near the surface and the steel bars in the upper level. They found that the stiffness of hybrid steel-GFRP reinforced concrete beams relatively increased after the steel bars had yielded, indicating that the GFRP bars became more effective. The hybrid beams had higher flexure capacity than either steel or GFRP-reinforced concrete beams. In hybrid steel-GFRP reinforced concrete beams, higher concrete strength increased the flexure strength and, to a smaller extent, the shear strength. Recently, Qu, Zhang and Huang [17] investigated experimentally and theoretically the structural behavior of concrete beams with hybrid steel-GFRP bars arranged in the same level with the GFRP bars placed at the corners. Their work demonstrated that applying moderate amounts of steel and GFRP reinforcements provided good ductility, serviceability and load carrying capacity compared to GFRP reinforced beams.

Implementing hybrid steel-FRP reinforcement has been also recognized in strengthening works. The technique known as near surface mounting (NSM) has been adopted for the strengthening of steelreinforced flexural beams. It is based on gluing FRP bars to the concrete near the external surfaces of the 
tensile zone by mounting the FRP bars in groves cut in the concrete surface $[18,19]$.

\section{RESEARCH SIGNIFICANCE}

The aim of the current work was to investigate the structural behavior of concrete beams reinforced with hybrid steel-GFRP reinforcement. The proposed system utilized the merits of steel with regard to ductility and stiffness and the non-corrosive nature of FRP composites. While, the main steel bars are adequately elevated towards the compression zone to increase the protective concrete cover, the GFRP bars are laid near the bottom surface to upgrade the structural performance in terms of strength and stiffness and to control cracking. The test parameters included the steel and GFRP reinforcement ratios and the configuration of the shear reinforcement to provide a practical solution for tying the hybrid reinforcement within the concrete section. The experimental results were used to verify the adequacy of an equation proposed to predict the ultimate loads.

\section{FLEXURE STRENGTH DESIGN MODEL}

The section under consideration is a hybrid steelGFRP reinforced concrete section subjected to pure bending moment. The flexure capacity of the hybrid test beam is governed by yielding of the steel reinforcement followed by concrete crushing, while the tensile stress in the GFRP bars $\left(f_{f}\right)$ is less than the design tensile strength $\left(f_{f u}\right)$. The presented flexure strength model assumes that the reduction of strength due to the elevation of the steel bars is compensated by the added GFRP reinforcement. The stress distribution in the concrete can be approximated according to the ACI318-95 code [16] stress block as can be seen in Fig. (1). The computation of the flexure strength of the hybrid cross section is based on the following assumptions: ( $i$ ) strain in the concrete and both the steel and GFRP reinforcement is proportional to the distance from the neutral axis, (ii) the maximum compressive strain at concrete crushing $\left(\varepsilon_{c u}\right)$ is taken 0.003 , (iii) the tensile strength of concrete is ignored and the tensile behavior of the GFRP reinforcement is linearly elastic till failure and (iv) perfect bond exists between concrete and the reinforcement. Based on the equilibrium of forces and strain compatibility conditions shown in Fig. (1), the following equations can be derived:

$$
\begin{aligned}
& A_{s} f_{y}+A_{f} f_{f}=0.85 f_{c} a b \\
& a=\left(A_{s} f_{y}+A_{f} f_{f}\right) / 0.85 f_{c} b \\
& \varepsilon_{c u} / \varepsilon_{f}=\mathrm{c} /\left(d_{f}-c\right) \\
& f_{f}=E_{f} \varepsilon_{c u}\left(\beta_{1} d_{f}-a\right) / a
\end{aligned}
$$

substituting (a) from Eq. (2) into Eq. (4) and rearranging the terms, a polynomial equation of the second degree ( $\mathrm{A} f_{f}{ }^{2}+\mathrm{B} f_{f}+\mathrm{C}=0$ ) is obtained. Solving for $f_{f}\left(f_{f}=\left[\left(\mathrm{B}^{2}-4 \mathrm{AC}\right)^{0.5}-\mathrm{B}\right] / 2 \mathrm{~A}\right)$ gives:


Fig. 1 Strain and stress distribution at ultimate condition

$f_{f}=\left[0.25\left(A_{r} f_{y}+E_{f} \varepsilon_{c u}\right)^{2}+\left(0.85 \beta_{1} f_{c} / \rho_{f}-A_{r} f_{y}\right) E_{f}\right.$
$\left.\varepsilon_{c u}\right]^{0.5}-0.5\left(A_{r} f_{y}+E_{f} \varepsilon_{c u}\right) \leq f_{f u}$
in which: $A_{r}=A_{s} / A_{f}$ and $\rho_{f}=A_{f} / b d_{f}$

The ultimate bending moment $(\mathrm{M})$ resisted by the section is given by:

$\mathrm{M}=A_{s} f_{y}\left(d_{s}-a / 2\right)+A_{f} f_{f}\left(d_{f}-a / 2\right)$

\section{EXPERIMENTAL WORK}

A total of twelve reinforced concrete beams were manufactured and tested. All beams were $1350 \mathrm{~mm}$ long with a cross section of $100 \mathrm{~mm}$ width and 200$\mathrm{mm}$ depth. The test beams were classified into four groups according to the configuration of the reinforcement as shown in Fig. (2). The first configuration described traditional steel reinforcement utilizing two $10 \mathrm{~mm}$ or $12 \mathrm{~mm}$ diameter steel bars as tension reinforcement (beams denoted B10 and B12). In the second configuration, the steel bars were elevated by $40 \mathrm{~mm}$ and shorter stirrups were used (beams denoted B10E and B12E). In the third configuration, a pair of $6 \mathrm{~mm}$ or $8 \mathrm{~mm}$ GFRP bars were laid near the bottom surface outside the elevated steel cage (beams denoted B10/6, B10/8, $\mathrm{B} 12 / 6$ and $\mathrm{B} 12 / 8)$, while in the fourth configuration, half of the stirrups were extended to enclose the GFRP bars (beams denoted B10/6S, B10/8S, B12/6S and B12/8S). Table (1) gives the geometrical design parameters including the reinforcement area, effective depth and the GFRP reinforcement ratio. In all test beams, two $8 \mathrm{~mm}$ mild steel bars were used as stirrup hangers along the shear span allowing singly reinforced sections within the constant moment region. The shear reinforcement consisted of $8 \mathrm{~mm}$ closed stirrups at $70 \mathrm{~mm}$ spacing along the shear span. The beams were tested until failure under fourpoint flexure loading according to the loading configuration and dimensions in Fig. (2). 
Mohamed A. Safan, "Behavior And Design Aspects Of Concrete Beams Reinforced With Hybrid ..."

Table 1. Geometrical design parameters of test beams

\begin{tabular}{cccccccccc}
\hline Beam & $\begin{array}{c}A s \\
(\mathrm{~mm} 2)\end{array}$ & $\begin{array}{c}d s \\
(\mathrm{~mm})\end{array}$ & $\begin{array}{c}A f \\
(\mathrm{~mm} 2)\end{array}$ & $\begin{array}{c}d f \\
(\mathrm{~mm})\end{array}$ & $\begin{array}{c}\rho s \\
(\%)\end{array}$ & $\begin{array}{c}\rho f \\
(\%)\end{array}$ & $\begin{array}{c}\rho e \\
(\%)\end{array}$ & $\begin{array}{c}\rho b \\
(\%)\end{array}$ & $\rho e / \rho b$ \\
\hline$B 10$ & 157 & 176 & -- & -- & 0.89 & -- & 0.89 & 2.12 & 0.42 \\
$B 10 E$ & 157 & 136 & -- & -- & 1.15 & -- & 1.15 & 2.12 & 0.54 \\
$B 12$ & 226 & 175 & -- & -- & 1.29 & -- & 1.29 & 2.53 & 0.51 \\
$B 12 E$ & 226 & 135 & -- & -- & 1.67 & -- & 1.67 & 2.53 & 0.66 \\
$B 10 / 8 S \& B 10 / 8$ & 157 & 136 & 100.6 & 178 & 1.15 & 0.57 & 1.26 & 2.12 & 0.60 \\
$B 10 / 6 S \& B 10 / 6$ & 157 & 136 & 56.6 & 179 & 1.15 & 0.32 & 1.22 & 2.12 & 0.58 \\
$B 12 / 8 S \& B 12 / 8$ & 226 & 135 & 100.6 & 178 & 1.67 & 0.57 & 1.78 & 2.53 & 0.71 \\
$B 12 / 6 S \& B 12 / 6$ & 226 & 135 & 56.6 & 179 & 1.67 & 0.32 & 1.74 & 2.53 & 0.69 \\
\hline
\end{tabular}
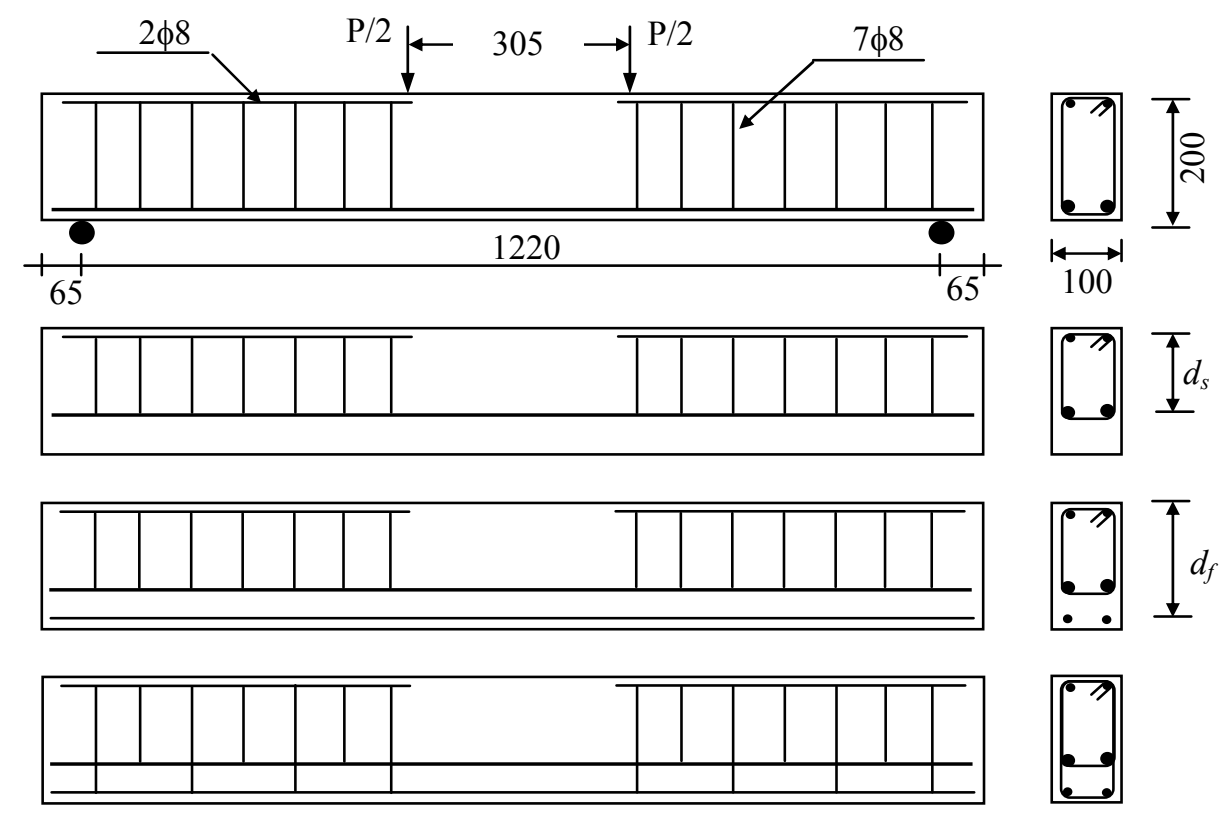

Fig. 2 Reinforcement details and test configuration

\subsection{Manufacturing of test beams Materials:}

Portland cement (CEM I - 42.5N) conforming to BS EN 197-1 [20] was used. The fine aggregate was natural siliceous sand with a fineness modulus of 2.72 and a specific gravity of 2.58. Crushed dolomite with a maximum nominal size of $25.4 \mathrm{~mm}$ was used as coarse aggregate. The particles contained moderate amounts of flaky and elongated particles. The coarse aggregate had a specific gravity of 2.75 and a crushing modulus of $16 \%$. The grading of the fine and coarse aggregates conformed to the limits of ASTM C33 [21]. Tension tests showed that the average yield strength (fy) of the high strength deformed bars used as main reinforcement was 530 $\mathrm{MPa}$ for the $10 \mathrm{~mm}$ bars and $470 \mathrm{MPa}$ for the $12 \mathrm{~mm}$ bars. The average yield strength of the $8 \mathrm{~mm}$ mild steel bars used for the stirrups and stirrup hangers was $305 \mathrm{MPa}$.

In-house manufactured $6 \mathrm{~mm}$ and $8 \mathrm{~mm}$ GFRP bars were produced and tested in tension according to the procedures described by Safan [22]. A simple hand-operated equipment was used to saturate the glass rovings in a polyester basin and then twist the fibers to an off-axis angle of 30 degrees to squeeze excessive resin. The produced bars were coated with sand to improve the bond strength. The fiber volume fraction in the produced bars was about $63 \%$. The test results showed that the guaranteed tensile strength for the $6 \mathrm{~mm}$ bars was $780 \mathrm{MPa}$ with a modulus of elasticity of $41 \mathrm{GPa}$. The corresponding values for the $8 \mathrm{~mm}$ bars were $755 \mathrm{MPa}$ and $39 \mathrm{GPa}$.

The cement content in the concrete mix was 350 $\mathrm{kg} / \mathrm{m}^{3}$, the ratio of the coarse aggregate to fine aggregate was 1.7 by weight and the water/cement ratio was 0.45 . A high range water reducer conforming to ASTM C-494 (type A and F) [23] was used to improve the workability of the mix at a dose of $0.5 \%$ by weight of cement.

\subsection{Preparation of test specimens}

Tight wooden forms with internal dimensions of $1350 \times 200 \times 100 \mathrm{~mm}$ were used in casting the beam test specimens. A thin layer of grease was applied to the internal surfaces to ensure easy stripping and to prevent water absorption. The reinforcements were placed inside the forms provided that a minimum clear concrete cover of $10 \mathrm{~mm}$ was applied to the stirrups. The concrete was mixed in a 60 liter 
capacity mechanical mixer. The concrete was pored in successive layers and each layer was thoroughly compacted using an electrical vibrator. The concrete was allowed to cure in the forms for two days after which the forms were stripped and the beams were cured under wet cloth for 7 days. Three $150 \times 300$ $\mathrm{mm}$ cylinders and three prisms $100 \times 100 \times 500 \mathrm{~mm}$ were cast to determine the concrete compressive strength $\left(f_{c}\right)$ and the fracture modulus.

\subsection{Test setup and procedure}

The test beams were stored in the laboratory atmosphere for 28 days before testing. The sides were painted in white to facilitate the detection of cracks. The beams were loaded in flexure under four-point loading along a clear span of $1220 \mathrm{~mm}$. The load was a applied by a means of a $100 \mathrm{kN}$ flexure machine and the applied load was distributed into two concentrated loads that were $305 \mathrm{~mm}$ apart allowing a shear span of $458 \mathrm{~mm}$. Two punched cupper disks were affixed to the two sides of the test beam at the level of the steel bars to measure the tensile strain by means of a $200 \mathrm{~mm}$ gage length demountable extensometer. The load was applied in load increments of $2 \mathrm{kN}$. At each load increment the midspan deflection was measured by means of a mechanical dial gage and the cracks were marked. A portable microscope was used to measure the maximum crack width at a service load corresponding to 60 percent of the theoretical ultimate load of the control beams E10 and E12. This load was $35 \mathrm{kN}$ for the beams reinforced with $10 \mathrm{~mm}$ steel bars and $42 \mathrm{kN}$ for the beams reinforced with $12 \mathrm{~mm}$ steel bars. Testing the concrete specimens showed that the 28-day compressive strength was $30 \mathrm{MPa}$ and the modulus of rupture was 3.4 MPa.

\section{ANALYSIS AND DISCUSSION OF RESULTS}

A proposed flexure strength design equation was used to predict the load carrying capacity of the steelFRP singly reinforced concrete beams subjected to bending. The design philosophy is based on modifying the traditional reinforcement configuration of a beam designed according to the requirements of the ACI318-95 code [16]. The steel bars are elevated to the desired level to increase the protecting concrete cover. Then, extra FRP reinforcement are introduced to compensate the strength loss and control cracking. In the current work, the tension steel bars were raised by $40 \mathrm{~mm}$ which is 23 percent of the effective depth of the control beam. Obviously, this ratio is sufficiently high to explore the efficiency of the investigated hybrid reinforcing system with regard to the significant influence of reducing the effective depth on the structural behavior in terms of strength and serviceability. Obviously, the percentage of the extra cover needed with respect to the effective depth in a real-practice design would be much smaller. However, the question about specifying a limit for this ratio remains unanswered. For this purpose, an effective reinforcement ratio $\left(\rho_{e}\right)$ is proposed. This ratio is expressed by Eq. (7) as the sum of the steel reinforcement ratio an equivalent FRP reinforcement ratio:

$\rho_{e}=\rho_{s}+\left(E_{f} / E_{s}\right) \rho_{f}$

in which: $\rho_{s}$ is the steel reinforcement ratio $\left(A_{s} / b d_{s}\right)$ and $\left(E_{f} / E_{s}\right)$ is a modular ratio for FRP and steel $\left(E_{s}=200 \mathrm{GPa}\right)$. It might be confusing that as the main steel bars are elevated, the steel reinforcement ratio is increased and the load carrying capacity is reduced. Thus, it should be emphasized that this ratio is implemented in this context only for the purpose of predicting the mode of failure of concrete beams reinforced with the described hybrid steel-FRP system. Following the guidelines of the ACI318-95 code [16], it is suggested that the effective reinforcement ratio may not exceed 0.75 of the balanced ratio of the steel reinforced section $\left(\rho_{b}\right)$ to guarantee ductile failure. In the current work, the values of the effective reinforcement ratio ranged between 0.42 and 0.71 of the balanced ratio as reported in Table (1).

\subsection{Cracking pattern and mode of failure}

Fig. (3) shows graphic representations of the cracking patterns of test beams upon failure. All beams failed in a ductile manner due to concrete crushing in the compressive zone after yielding of the steel bars. This result indicated that the $0.75 \rho_{b}$ limit for the effective reinforcement ratio was suitable to guarantee ductile failure of the hybrid reinforced beams. All beams, except beams B10E and B12E, were cracked in a similar fashion. Cracking was initiated along the maximum moment region and propagated upwards with loading, while other flexure cracks formed outside the maximum moment region. Failure occurred as one or more cracks in the maximum moment region extended in the compression zone causing concrete to crush due to excessive strain. On the other hand, beams B10E and B12E demonstrated a significantly lower number of flexure cracks at failure. The cracks were initiated in the maximum moment region and propagated upwards with loading. Once the cracks extended to the level of the steel bars, other cracks branched from the tip of a root crack while other new cracks were initiated at the level of the steel bars and propagated upwards with loading. However, beams B10E and B12E still failed in a ductile manner due to concrete crushing. The cracking loads $\left(P_{c r}\right)$ along with the number of cracks at failure are reported in Table (2). It can be shown that the cracking loads were significantly smaller in all beams with elevated steel 
Mohamed A. Safan, "Behavior And Design Aspects Of Concrete Beams Reinforced With Hybrid ..."

Table 2. Theoretical and experimental test results

\begin{tabular}{|c|c|c|c|c|c|c|c|c|c|c|c|}
\hline \multirow[b]{2}{*}{ Beam } & \multicolumn{3}{|c|}{ Theoretical } & \multicolumn{7}{|c|}{ Experimental } & \multirow[b]{2}{*}{$\frac{P u \text { (exp. }}{P u \text { (theo. }}$} \\
\hline & $\begin{array}{c}P_{u} \\
(\mathrm{kN})\end{array}$ & $\begin{array}{c}f_{f} \\
(\mathrm{MPa})\end{array}$ & $\begin{array}{c}T_{f} / T_{t} \\
(\%)\end{array}$ & $\begin{array}{c}P_{c r} \\
(\mathrm{kN})\end{array}$ & $\begin{array}{c}P_{y} \\
(\mathrm{kN})\end{array}$ & $\begin{array}{c}P_{u} \\
(\mathrm{kN})\end{array}$ & $\begin{array}{l}\text { No. of } \\
\text { cracks }\end{array}$ & $\begin{array}{l}\text { crack } \\
\text { width } \\
(\mathrm{mm})\end{array}$ & $\begin{array}{c}f_{f} \\
(\mathrm{MPa})\end{array}$ & $\begin{array}{l}T_{f} / T_{t} \\
(\%)\end{array}$ & \\
\hline B10 & 58.0 & -- & -- & 17.5 & 55.0 & 63.7 & 10 & 0.14 & -- & -- & 1.10 \\
\hline $\mathrm{B} 10 / 8 \mathrm{~S}$ & 63.7 & 281 & 25.3 & 11.0 & 60.0 & 63.0 & 13 & 0.26 & 273 & 24.8 & 0.99 \\
\hline B $10 / 8$ & 63.7 & 281 & 25.3 & 11.3 & 50.0 & 59.6 & 12 & 0.28 & 226 & 21.4 & 0.94 \\
\hline $\mathrm{B} 10 / 6 \mathrm{~S}$ & 57.0 & 334 & 18.5 & 11.0 & 50.0 & 61.6 & 13 & 0.26 & 448 & 23.3 & 1.08 \\
\hline B10/6 & 57.0 & 334 & 18.5 & 11.0 & 50.0 & 58.8 & 11 & 0.30 & 379 & 20.5 & 1.03 \\
\hline $\mathrm{B} 10 \mathrm{E}$ & 43.3 & -- & -- & 10.5 & 40.0 & 44.0 & 6 & 0.62 & -- & -- & 1.02 \\
\hline B12 & 71.4 & -- & -- & 20.0 & 70.0 & 74.6 & 14 & 0.12 & -- & -- & 1.04 \\
\hline B12/8S & 68.6 & 225 & 17.6 & 12.0 & 65.0 & 71.4 & 13 & 0.23 & 265 & 20.1 & 1.04 \\
\hline B12/8 & 68.6 & 225 & 17.6 & 11.8 & 60.0 & 64.0 & 13 & 0.23 & 158 & 13.0 & 0.93 \\
\hline $\mathrm{B} 12 / 6 \mathrm{~S}$ & 63.3 & 262 & 12.2 & 10.0 & 60.0 & 65.1 & 12 & 0.25 & 308 & 14.1 & 1.03 \\
\hline $\mathrm{B} 12 / 6$ & 63.3 & 262 & 12.2 & 9.0 & 57.5 & 61.4 & 12 & 0.25 & 213 & 10.2 & 0.97 \\
\hline $\mathrm{B} 12 \mathrm{E}$ & 52.8 & -- & -- & 11.0 & 50.0 & 51.6 & 4 & 0.58 & -- & -- & 0.98 \\
\hline
\end{tabular}
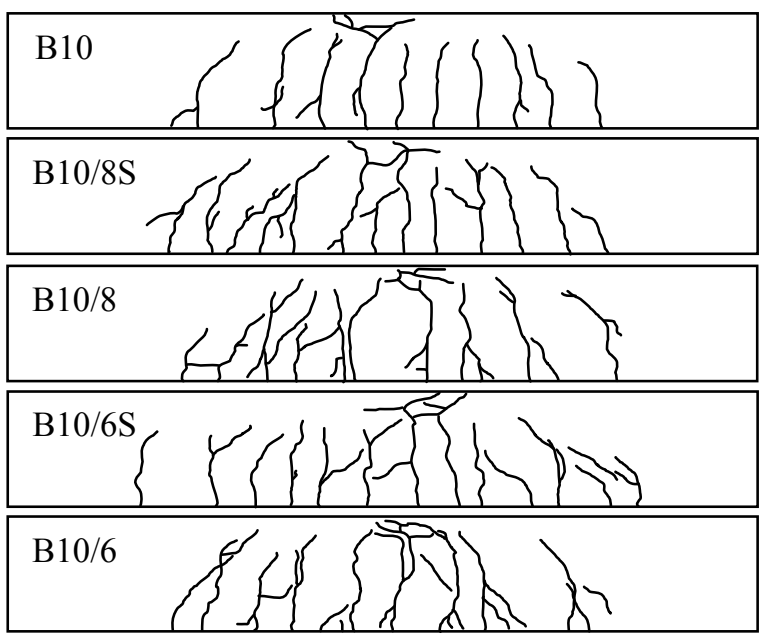

B10E

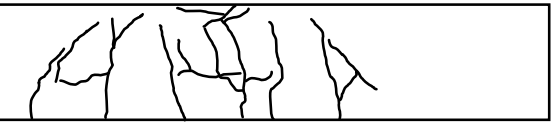

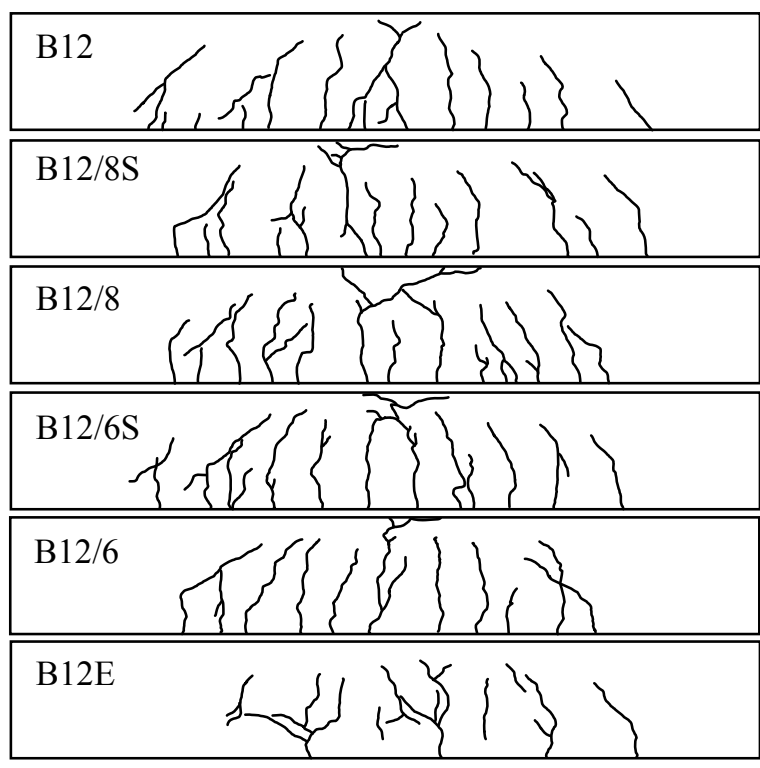

Fig. 3 Cracking patterns at failure

bars and were not influenced by any of the test parameters. On the other hand, the number of cracks at failure was either higher or almost the same as in the counterpart control beams B10 and B12 due to the use of GFRP reinforcement. The measured maximum crack width values are reported in Table (2). It can be shown that the crack widths were four to five times bigger in beams $\mathrm{B} 10 \mathrm{E}$ and $\mathrm{B} 12 \mathrm{E}$ compared to the control beams B10 and B12. Actually, the measured crack widths were sufficiently higher than the $0.4 \mathrm{~mm}$ maximum limit allowed by the ACI 224R-01 report [24] for interior exposure. The use of the GFRP reinforcement was quite effective in controlling the crack width to be generally less than the maximum limit of $0.3 \mathrm{~mm}$ for exterior exposure.

\subsection{Load-deflection response}

Fig. (4) shows the load-deflection relationships for the tested beams. Control beams E10, E12, E10E and E12E demonstrated similar response. The loaddeflection curve consisted of three segments describing three stages denoting pre-cracking, postcracking and yielding of steel. In the pre-cracking stage, the beams showed the highest stiffness that was not significantly influenced by any of the test parameters. Once the beam was cracked, the stiffness was reduced in the second stage that continued until the steel yielded. A severe reduction of stiffness can be observed due to elevating the steel bars in beams $\mathrm{B} 10 \mathrm{E}$ and $\mathrm{B} 12 \mathrm{E}$ compared to the control beams B10 and B12. This was attributed to the formation of considerably wider cracks distributed along a shorter portion of the beam span. Also, the cracking patterns 

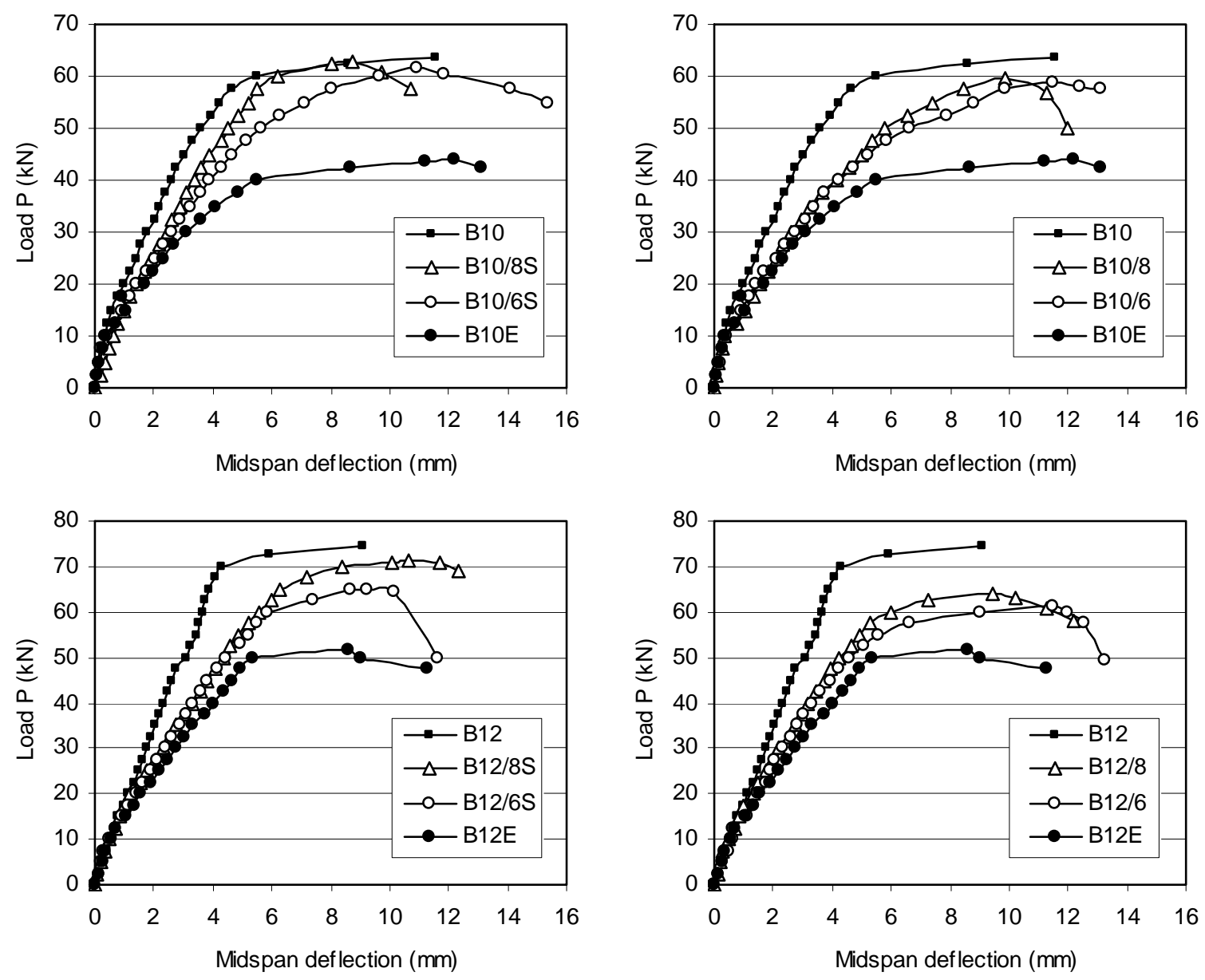

Fig. 4 Load-deflection relationships for test beams

in Fig. (3) showed that the initial cracks branched into secondary flexure cracks at the level of the steel bars which means that the steel bars were not effective in restricting the cracking in beams $\mathrm{B} 10 \mathrm{E}$ and B12E. Once a control beam had yielded, the stiffness was considerably degraded and there was only a limited increase in the applied load until the ultimate capacity was reached and concrete began to crush.

Compared to the stiffness of control beams B10E and $\mathrm{B} 12 \mathrm{E}$, the stiffness of the hybrid beams was higher. Within serviceability load limits $(60 \%$ of the theoretical ultimate load of beams B10 and B12), the post-cracking stiffness was typical in all test beams having the same steel reinforcement ratio and was independent of both the GFRP reinforcement ratio and the configuration of the stirrups. Above this limit, the stiffness of beam B10/8S was higher than that of beam B10/8. On the other hand, the postcracking stiffness in the following beam couples (B10/6S, B10/6), (B12/8S, B12/8) and (B12/6S, $\mathrm{B} 12 / 6)$ was the same. While the GFRP-to-steel reinforcement ratios for those beam couples were
$0.36,0.44$ and 0.25 , respectively, this ratio in beams $\mathrm{B} 10 / 8 \mathrm{~S}$ and $\mathrm{B} 10 / 8$ was as high as 0.64 . It can be concluded that confining the GFRP bars was effective in terms of increased post-cracking stiffness for relatively higher GFRP-to-steel reinforcement ratios.

\subsection{Flexure capacity}

The theoretical and experimental ultimate loads $\left(P_{u}\right)$ are reported in Table (2) along with the theoretical and experimental values of the tensile stress in the GFRP bars $\left(f_{f}\right)$ at ultimate load and the ratio of tensile force in the GFRP bars at failure $\left(T_{f}\right)$ to the total tensile force provided by the hybrid reinforcement $\left(T_{t}\right)$. The reported results indicated that the ultimate loads were reasonably predicted by the derived design equation. The experimental values of the tensile stress in the GFRP bars were calculated by substituting the experimental ultimate moments in Eq. (6) and solving for $f_{f}$. The reported experimental results showed that the ultimate loads for beams $\mathrm{B} 10 / 8 \mathrm{~S}, \mathrm{~B} 10 / 8, \mathrm{~B} 10 / 6 \mathrm{~S}$ and $\mathrm{B} 10 / 6$ were $99,94,97$ and 92 percent of the ultimate load of the control 
beam B10. The corresponding values for beams $\mathrm{B} 12 / 8 \mathrm{~S}, \mathrm{~B} 12 / 8, \mathrm{~B} 12 / 6 \mathrm{~S}$ and $\mathrm{B} 12 / 6$ compared to the control beam B12 were $96,86,87$ and 82 percent. On the other hand, the ultimate loads of beams B10E and B12E were limited to 69 percent of the corresponding ultimate loads in beams B10 and B12. These results indicated that the GFRP bars in a hybrid reinforcement system were quite effective in maintaining an adequate level of flexure capacity and the efficiency was increased for the investigated higher GFRP-to-steel ratios and when the stirrups confined the GFRP bars. The reported relatively high levels of flexure capacity were achieved while the experimental tensile stresses in the GFRP bars at failure were limited to $21-57$ percent of their guaranteed tensile strength. This limited tensile stress level in the GFRP bars is quite convenient knowing that the ACI 440.1R-06 guide [4] adopted a maximum reduction factor of 0.7 for reducing the tensile strength of GFRP due to long-term environmental and temperature effects.

Another important parameter to consider was that the theoretical tensile stresses in the GFRP bars at ultimate load were $30-43$ percent of the tensile strength. It can be seen that while the experimental ultimate load of beam B10/6S was only 8 percent higher than the theoretical load, the experimental stress in the GFRP bars was 34 percent higher than the theoretical stress. This was attributed to the fact that the tensile force provided by the steel bars at failure can be no more than the yield stress times the area of the steel bras. Thus, any further increase in the ultimate load upon steel yielding is carried by the GFRP bars. As the tensile force in the GFRP bars represented a fraction of the total force, a given increase in the total load imposed significant percentage increase in the tensile stress in the GFRP bars. This behavior explained why the stiffness degradation upon yielding of steel in the hybrid beams was not as the severe as in the steel reinforced beams.

Because the mechanical characteristics of FRP bars can significantly differ in terms of tensile strength and modulus of elasticity, the capability of the FRP reinforcement to share in the flexure capacity is better reflected by the ratio $\left(T_{f} / T_{t}\right)$. The reported values of this ratio for beams $\mathrm{B} 10 / 8 \mathrm{~S}$, $\mathrm{B} 10 / 8, \mathrm{~B} 10 / 6 \mathrm{~S}, \mathrm{~B} 10 / 6 \mathrm{~S}$ and $\mathrm{B} 12 / 8 \mathrm{~S}$ suggested that adequate levels of the flexure capacity can be attained even if the GFRP reinforcement area was as low as $36 \%$ of the steel reinforcement area. Further, the ultimate load results of beams B12/8S and B12/8 showed that extending the shear stirrups to confine the GFRP bars was necessary to develop higher flexure capacity as the steel ratio increased.

\section{CONCLUSIONS}

The behavior of hybrid steel-GFRP reinforced concrete beams has been analyzed in this paper. The hybrid reinforcement system comprises steel bars provided with increased concrete cover to increase the corrosion resistance and GFRP bars near the bottom surface to compensate the loss of the flexure strength and to control cracking. The structural behavior in terms of the load carrying capacity, deflection, crack width and failure mode was evaluated experimentally. A design equation to predict the ultimate load of hybrid reinforced beams was presented. Based on the available test results the following conclusions could be drawn:

1. All test beams including the hybrid reinforced beams failed in a ductile manner due to concrete crushing after yielding of the steel reinforcement. Limiting the effective reinforcement ratio to 75 percent of the balanced ratio of the steel beam was suitable to guarantee ductile failure of the hybrid reinforced beams.

2. The use of the GFRP reinforcement was quite effective in controlling the crack width to acceptable serviceability limits.

3. Confining the GFRP bars was effective in terms of increased post-cracking stiffness for relatively higher GFRP-to-steel reinforcement ratios.

4. The GFRP bars in a hybrid reinforcement system were quite effective in maintaining an adequate level of flexure capacity and the efficiency was increased for higher GFRP-to-steel ratios and when the shear stirrups confined the GFRP bars.

5. Adequate levels of the flexure capacity can be attained even if the GFRP reinforcement area was as low as $36 \%$ of the steel reinforcement area. Further, extending the shear stirrups to confine the GFRP bars was necessary to develop higher flexure capacity as the steel ratio increased.

6. The proposed design equation provided satisfactory predictions of the flexure capacity of the hybrid reinforced beams.

\section{REFERENCES}

[1] ACI 222R-01 (2001) "Protections of metals in concrete against corrosion" American Concrete Institute, ACI Committee 222, $41 \mathrm{p}$.

[2] Qu, W. J. and Zhang, Y. (2001) "Method for durability maintenance of concrete bridge" J. China Railway Society, Vol. 23, No. 1, pp. 98102 (in Chinese).

[3] Clarke J. L. (1993) "Non-ferrous reinforcement for structural concrete" Concrete 2000, Editor Dhir, R. K. and Jones, M. R., E\&FN Spon., London, pp. 85-97.

[4] ACI 440.1R-06 (2006) "Guide for the design and construction of structural concrete reinforced 
with FRP bars" American Concrete Institute, ACI Committee 440, $44 \mathrm{p}$.

[5] ACI 440R-96 (1996) "State-of-the-art report of fiber reinforced plastic (FRP) reinforcement for concrete structures" American Concrete Institute, ACI Committee 440, $65 \mathrm{p}$.

[6] Bank, L. C. (1993) "Properties of FRP Reinforcement for Concrete" Fiber-ReinforcedPlastic (FRP) Reinforcement for Concrete Structures: Properties and Applications, Developments in Civil Engineering, V. 42, A. Nanni, ed., Elsevier, Amsterdam, pp. 59-86.

[7] Ehsani, M. R., (1993) "Glass-Fiber Reinforcing Bars" Alternative Materials for the Reinforcement and Prestressing of Concrete, Clarke, J. L., Blackie Academic \& Professional, London, pp. 35-54.

[8] Alsayed, S. H. (1998) "Flexural behavior of concrete beams reinforced with GFRP bars" Cement and Concrete Composites, 20, pp. 1-11.

[9] Safan, M. and Afify, M. (2005) "Behavior of concrete beams reinforced with in-house manufactured GFRP bars" Proceedings of the Fourth Middle East Symposium on Structural Composites for Infrastructure Applications, MESC-4, Alexandria, Egypt, 2005.

[10]Leung, H. Y. and Balendran, R. V (2003) "Flexural behavior of concrete beams internally reinforced with GFRP rods and steel rebars" Structural Survey, Vol. 21, No. 4, pp.146-157.

[11] Arya, C. ; Ofori, F.K. and Pirathapan, G. (1995) "FRP rebars and the elimination of reinforcement corrosion in concrete structures" Non-metallic (FRP) Reinforcement in Concrete Structures, Ed. Taerwe. L., RILEM, E\&FN Spon., London, pp. 227-234.

[12] Comite Euro-International du Beton (1992) "Durable concrete structures" Thomas Telford, London, UK.

[13]BS8110, (1985) "Structural use of concrete, part1: Code of practice for design and construction and Part 2: Code of practice for special circumstances" British Standards Institution, London.

[14] Tan, K. H. (1997) "Behavior of hybrid FRP-steel reinforced concrete beams" Proceedings of the 3rd International Symposium on Non-Metallic (FRP) Reinforcement for Concrete Structures (FRPRCS-3), Japan Concrete Institute, Sapporo, pp. $487-494$.

[15] Aiello, M. A. and Ombres, L. (2002) "Structural performances of concrete beams with hybrid fiber reinforced polymer-steel reinforcements" J. Composite Construction, Vol. 6, No. (2), pp. 133-140.

[16] ACI 318-95 (1995) "Building code requirements for reinforced concrete" American Concrete Institute, ACI 318-95 and commentary, 369 p.
[17]Qu, W.; Zhang, X. and Huang, H. (2009) "Flexural behavior of concrete beams reinforced with hybrid (GFRP and steel) bars". Journal of composites for construction, ASCE, DOI: 10.1061/(ASCE)CC.1943-5614.0000035, pp. 350-359.

[18] De Lorenzis, L. ; Nanni, A. and La Tegola, A. (2000) "Strengthening of Reinforced Concrete Structures with Near Surface Mounted FRP Rods" International Meeting on Composite Materials, PLAST 2000, Milan, Italy, 8p.

[19] Kamal, M. M. ; Safan, M. A. and Salama, R. A. (2008) "Experiments on strengthened concrete beams with hybrid steel-GFRP reinforcement" Engineering Research Journal, Menoufia University, Vol. 31, No. 2, ISSN 1110-1180, pp. 201-210.

[20]BS-EN 197-1 (2000) "Cement: composition, specifications, and conformity criteria for common cements" $52 \mathrm{p}$.

[21]ASTM C33 (2001) "Standard specification for concrete aggregates" $8 \mathrm{p}$.

[22] Safan, M. (2004) "Mechanical properties of locally produced hybrid FRP bars as concrete reinforcement" Proceedings of the International Conference on Future Vision and Challenges for Urban Development, Housing \& Building Research Center (HBRC), Egypt.

[23] ASTM C494 (1999) "Standard specification for chemical admixtures for concrete" $9 \mathrm{p}$.

[24]ACI 224R-01 (2001) "Control of cracking in concrete structures" American Concrete Institute, ACI Committee 224, 46 p. 